\title{
Erratum to: Curcumin induces G2/M arrest, apoptosis, NF-кB inhibition, and expression of differentiation genes in thyroid carcinoma cells
}

\author{
Suzan Schwertheim ${ }^{1}(D)$ Frederik Wein ${ }^{2}$ - Klaus Lennartz ${ }^{2} \cdot$ Karl Worm $^{1}$ • \\ Kurt Werner Schmid ${ }^{1,3} \cdot$ Sien-Yi Sheu-Grabellus ${ }^{1}$
}

Published online: 22 April 2017

(C) Springer-Verlag Berlin Heidelberg 2017

\section{Erratum to: J Cancer Res Clin Oncol \\ DOI 10.1007/s00432-017-2380-z}

Unfortunately, in the original publication of the article, Fig. 7 was published in low resolution. The higher resolution figure is given below.

The online version of the original article can be found under doi:10.1007/s00432-017-2380-z.

Suzan Schwertheim

suzan.schwertheim@uk-essen.de

1 Institute of Pathology, University Hospital of Essen, University of Duisburg-Essen, Hufelandstr. 55, 45122 Essen, Germany

2 Institute of Cell Biology (Cancer Research), Medical Faculty, University of Duisburg-Essen, Essen, Germany

3 West German Cancer Centre Essen (WTZE), Essen, Germany 
a

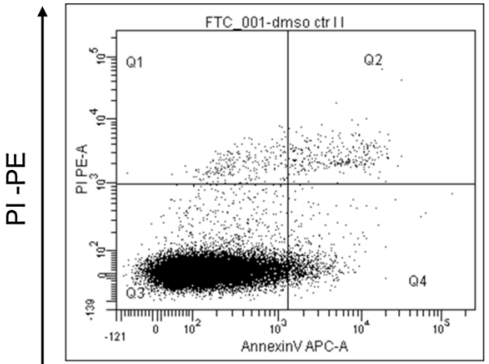

$50 \mu \mathrm{M}$

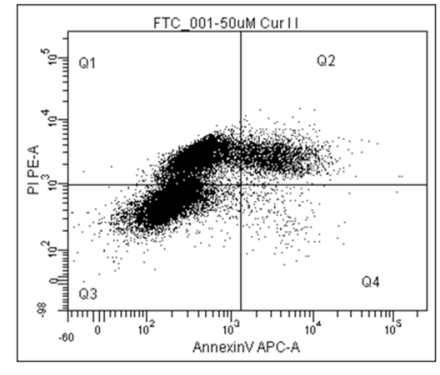

$\log _{10^{5}}$

Annexin V -APC

$50 \mu \mathrm{M}$; without Annexin $\mathrm{V}$ or PI

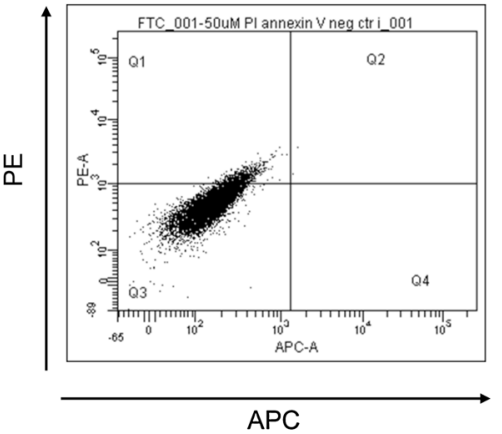

b

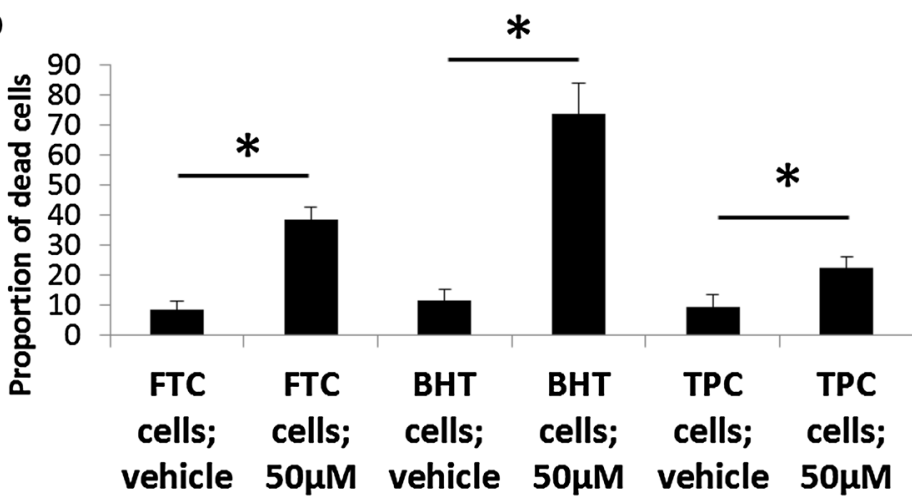

Fig. 7 Induction of apoptosis by curcumin. Flow cytometric analyses of the cell lines FTC-133, BHT-101 and TPC-1 display an increased proportion of Annexin V+and PI + cells after exposure to $50 \mu \mathrm{M}$ curcumin for $16 \mathrm{~h}$. One representative example for FTC-133 cells is displayed in a. To illustrate the autofluorescent cell signal after curcumin treatment, a condition without the addition of Annexin V or PI was added (right dotplot). A diagram summarizing all three independent biological replicates are displayed in $\mathbf{b}$. Statistical significance is indicated; $* p<0.05$ 